\begin{tabular}{|c|c|c|c|c|c|}
\hline JRL & Vol. 13 & No.2 & Hal. 182 - 193 & $\begin{array}{c}\text { Jakarta, } \\
\text { Desember 2020 }\end{array}$ & $\begin{array}{c}\text { p-ISSN : 2085.38616 } \\
\text { e-ISSN : 2580-0442 }\end{array}$ \\
\hline
\end{tabular}

\title{
APLIKASI OTOMATISASI POMPA KIMIA OKSIDATOR MENGGUNAKAN MODUL PLC SRB121FU PADA UNIT PENYARINGAN PENDAHULUAN ARSINUM SWRO
}

\author{
Imam Setiadi, S.Kom dan Ayudia Mutiara Fani, ST, MT \\ Pusat Teknologi Lingkungan, Badan Pengkajian dan Penerapan Teknologi., \\ Gedung 820 Geostek, Kawasan PUSPIPTEK, Tangerang Selatan, Banten \\ 15314 \\ imam.setiadi@bppt.go.id, ayudia.mutiara@bppt.go.id
}

\begin{abstract}
Abstrak
Kebutuhan masyarakat terhadap air minum yang berkualitas serta akses yang mudah untuk mendapatkanya dan kesadaran mengkonsumsi air minum yang sehat, mendorong semakin banyak inovasi teknologi penyediaan air minum mulai dari yang sederhana bersifat konvensional hingga teknologi modern. Didalam teknologi modern, agar dapat beroperasi dengan baik perlu adanya kontrol yang baik agar unit mesin penyedia air itu dapat bekerja maksimal dan berkesinambungan. Tujuan penelitian ini adalah untuk merancang kontrol otomatisasi pompa oksidator pada unit penyaringan pendahuluan menggunakan modul PLC agar menjaga efisisiensi suplai bahan kimia oksidasi pada air baku Arsinum. Metode yang digunakan pada aplikasi ini adalah kombinasi 1 buah pressure switch, 2 buah level kontrol pada tangki air baku dan tangki air bersih serta 1 buah modul plc smart relay SRB121FU untuk mengontrol pompa injeksi larutan oksidator bekerja bersamaan dengan pompa air baku ketika melakukan penyaringan. Hasil penelitian menunjukkan bahwa pemasangan modul PLC Smart Relay dapat mengontrol tangki air baku dan tangki air bersih pada proses pretreatment sehingga dapat diperoleh efisiensi pemakaian bahan kimia oksidator pada penolahan air minum ini secara keseluruhan.

Katakunci : air minum, kontrol, efisiensi, pressure switch, PLC
\end{abstract}




\title{
APPLICATION OF AUTOMATIC CHEMICAL OXIDATOR PUMPS USING PLC MODULE SRB121FU IN PRELIMINARY SCREENING UNIT ARSINUM SWRO
}

\begin{abstract}
In Accordance with high demand of accessibility to get healthy drinking water and awareness of consuming healthy drinking water encourage an innovation drinking water supply technology. Starting from the conventional to the modern technology, all are offered to the public. With modern technology, in order to operate properly must have good control, so that the water supply machine unit can work optimally and sustainably. The aim of this research is to design the automatic control of the oxidator pump in the preliminary filtering unit using a PLC module to maintain the efficiency supply of oxidizing chemicals on Arsinum raw water. The method used in this application is a combination of 1 pressure switch, 2 control levels in the raw water tank and clean water tank and 1 SRB121FU smart relay PLC module to control the oxidizer solution injection pump that works in conjunction with the raw water pump when filtering. The results showed that the installation of the PLC Smart Relay module can control the raw water tank and clean water tank in the pretreatment process so that the overall efficiency of using oxidizing chemicals in drinking water treatment can be obtained.
\end{abstract}

Keywords: drinking water, control, pressure swich, PLC 


\section{PENDAHULUAN}

\subsection{Latar Belakang}

Dari sekian banyak teknologi penyedia air minum, yang tersedia dipasaran baik dalam maupun luar negeri penyaringan dengan menggunakan teknologi membrane adalah yang paling relevan terhadap ketersediaan lahan, hanya membutuhkan lahan yang relative kecil cukup pada kisaran $3 \times 4$ meter sudah dapat menempatkan unit penyedia air siap minum dengan kapasitan $5 m^{3} /$ hari.

\section{Dengan}

kemampuan memproduksi air minum dalam waktu yang singkat dengan kualitas hasil olahan yang baik, maka teknologi ini menjadi pilihan tepat untuk mengatasi keterbatasan akses akan air minum bagi masyarakat, terutama masyarakat pesisir atau kepulauan seperti studi kasus pada makalah ini yaitu di Sekolah Seminari St. Yohanes Maria Vianney di daerah pesisir Selatan Kepulauan Tanimbar tepatnya di Jalan Misi Olilit Barat, Desa Olilit Barat, Kecamatan Tanimbar Selatan, Kabupaten Maluku Tenggara Barat, Provinsi Maluku. Karena berada tepat di tepi laut, setiap sumur yang ada di lingkungan sekolah ini akan dipengaruhi kondisi pasang surut air laut dimana penyediaan air minum menjadi kendala karena tidak tersedianya air baku air tawar sebagai bahan baku air minum. Dengan sumber air yang digunakan sebagai air baku terdiri dari berbagai sumber seperti sumur pasang surut dan PDAM dengan kandungan padatan terlarut yang variatif.
Kemampuan

mereduksi

material polutan yang terdapat pada air baku yang dilakukan oleh membrane dalam hal ini adalah sea water reverse osmosis (SWRO) membrane tersebut adalah sangat baik, dengan porositas sebesar 0,001 mikron. Dari semua molekul polutan yang memiliki dimensi lebih besar dari molekur air pada air bakui dipastikan 99,4\% tidak dapat menembus selaput membrane. (Spesifikasi FILMTEC ${ }^{\text {TM }}$ SW30-4040 Membranes)

$$
\text { Untuk menjaga agar }
$$

permukaan membrane tetap bebas dari polutan-polutan kasar, koloid, mikroba, jamur dan mikroorganisme yang dapat tumbuh dipermukaan membrane hingga dapat menurunkan kemampuan mereduksi polutan, perlu tambahan unit pretreatment atau penyaringan pendahuluan yang diharapkan mampu menghilangkan polutan kasar dan mikrooganisme yang ada pada air baku yang dapat merusak permukaan membrane. Penyaringan pendahuluan ini berupa dari penyaringan cepat yang beoperasi secara konvensional menggunakan media isian berupa pasir kuarsa, manganese zeolite dana arang aktif.

Unit penyaringan pendahuluan ini dilengkapi pompa kimia disinfeksi yang terhubung secara interlock dengan pompa air baku filtrasi. Air baku dipompakan kedalam tabungtabung filtrasi dengan diinjeksikan bahan disinfeksi berupa larutan $\mathrm{KMnO}_{4}$ atau larutan PK yang mana merupakan oksidator yang dengan konsentrasi tertentu dapat mengoksidasi mikroorganisme pada 
air baku dan mengoksidasi logamlogam yang terlarut pada air baku sehingga sisa pengotor hasil oksidasinya dapat tersaring pada unit penyaringan pendahuluan dengan baik dan menghasilkan air bersih sebagai bahan baku air minum.

Untuk menjaga kestabilan pasokan larutan oksidator kedalam air baku dibutuhkan kontrol yang terintegrasi antara pompa umpan dengan pompa oksidator ini dibutuhkan supaya pompa oksidator hanya mensuplai bahan okdasinya ketika pompa air baku bekerja.

Semua kontrol dilakukan pada panel pompa air baku menggunakan modul PLC SRB201FU dari pabrikan Shcneider Electric.

\subsection{Tujuan Penelitian}

Tujuan dari aplikasi ini adalah merancang kontrol otomatisasi pompa oksidator pada unit penyaringan pendahuluan menggunakan modul PLC agar menjaga efisisiensi suplai bahan kimia oksidasi pada air baku Arsinum.

\section{PERALATAN DAN METODOLOGI}

\subsection{Peralatan}

a. Pompa Sumur atau air baku

Pompa air adalah mesin yang dapat memindahkan sejumlah volume air melalui ruang hisap (suction) menuju ruang pengeluaran (discharge) dengan menggunakan impeller (wikikomponen). Energi yang diperlukan untuk memutar impeler didapat dari motor listrik yang shaftnya dikopel menjadi satu dengan impeler, sehingga dapat memindahkan fluida. Untuk aplikasi sumur dalam, pompa yang digunakan adalah tipe celup (submersible deep well) yang mempunyai kemampuan tekanan tinggi. Cara kerja pompa ini adalah mendorong air dari bawah ke atas sehingga tidak memerlukan pipa hisap.(http://jakartapiranti)

b. Pompa kimia

Pompa ini disebut juga pompa Dozing karena mempunyai kemampuan menginjeksi larutan kimia ke dalam air baku dengan dosis tertentu. Pompa kimia yang diaplikasikan menggunakan merek Pulsafeeder dengan seri Chem-Tech 100/30, menggunakan mekanikal diapram dan peristaltic metering pump sebagai mekanisme pepompaanya. Kapasitas $30 \mathrm{gpd}$ atau 0,47 I/jam, tekanan maksimum 100 psi atau 7 bar. Bekerja pada voltase 230 Volt 50 cycles, 1/60 HP.

\section{c. Pressure switch}

Pada umumnya ada beberapa jenis kontrol yang dipakai untuk mengatur operasi pompa, diantaranya pressure switch dan level control. Pressure switch (bekerja berdasarkan tekanan air), sedangkan level kontrol berdasarkan tinggi muka air. Prinsip kerja pressure switch adalah bila tekanan air meningkat, membran akan terdorong ke dalam, berikutnya pegas akan terdorong juga, tuas akan terdorong dan akan mendorong pegas daun, pegas daun yang mendorong tuas terakhir yang akan menutup poin kontak. 


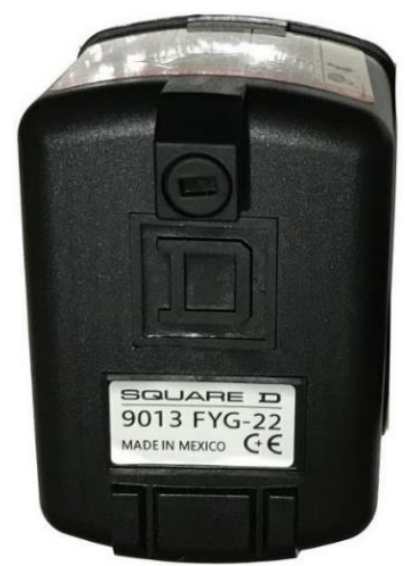

Gambar 1. Pressure switch

Bila ada pemakain air, tekanan air akan berkurang, membran akan tertarik keluar. Pegas spiral juga akan mengembang, tuas akan ikut bergerak, pagas daun akan terdorong juga. Pegas daun akan menarik tuas dan membuka poin kontak.
Pegas daun, berfungsi membedakan antara set point OFF dan $\mathrm{ON}$, tekanan yang umum dipakai $4 \mathrm{~kg} / \mathrm{cm} 2$ untuk OFF dan $2.7 \mathrm{~kg} / \mathrm{cm} 2$ untuk ON. Gap ini akan memberikan jeda untuk ON dan OFF.

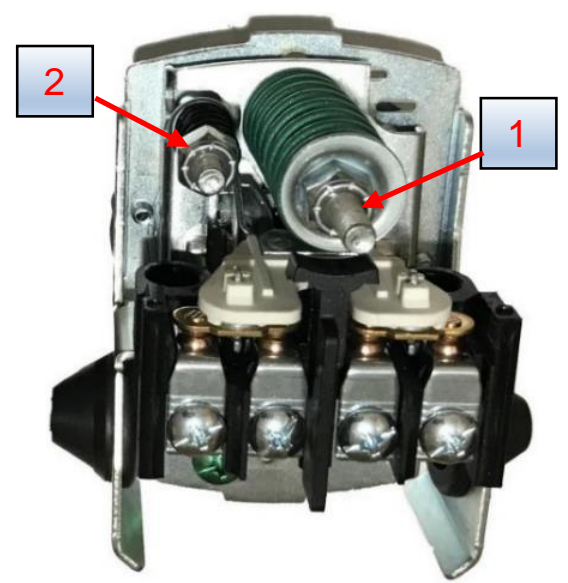

Gambar 2. Bagian dalam terminal pressure switch

Komponen yang terdapat pada gambar dibawah adalah :

1. Set point 1 untuk mengatur range tekanan operasi untuk membuka
(Open) poin kontak pada tekanan tinggi.

2. Set point 2 untuk mengatur diffrential tekanan operasi untuk 
menutup (Closed) poin kontak pada tekanan rendah.

3. Mode kontak yang digunakan adalah terminal 1 dan 3 akan terbuka atau tertutup dengan terminal 2 dan 4 saat tekanan mencapai $4 \mathrm{kgf} / \mathrm{cm} 2$.

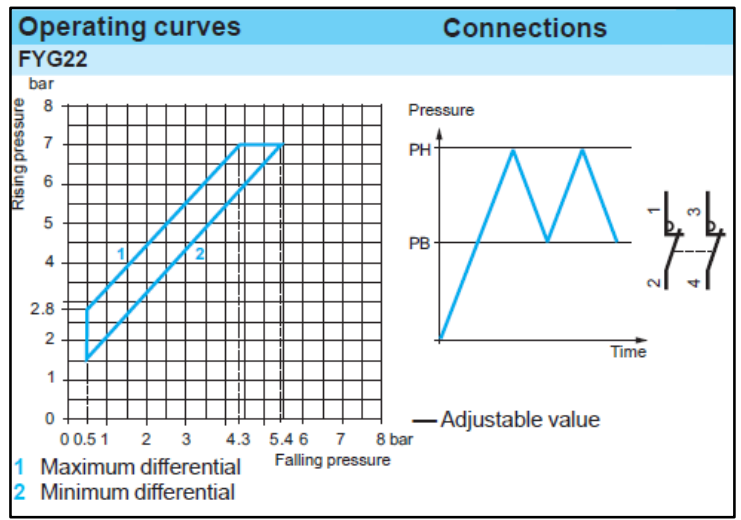

Gambar 3. Set point tekanan dan terminal

d. Kontaktor

Kontaktor adalah peralatan listrik yang bekerja berdasarkan induksi magnetis. Di dalam kontaktor terdapat kumparan yang jika dialiri listrik maka akan timbul medan magnet pada batang intinya.(Sugeng, Yusril, 2014) Akibat dari gaya magnet tadi akan menarik kontak pada bagian atas kontaktor, sehingga kontak normally open akan terhubung, demikian sebaliknya kontak normally close menjadi tidak terhubung.

Komponen penting yang terdapat pada kontaktor adalah:

1. Kumparan magnet dengan symbol A1 dan A2

2. Tiga pasang kontak utama normally open , 1-2, 3-4, 5-6

3. Dua pasang kontak bantu (auxiliary) 13-14 NO, 21-22 NC.

e. Modul PLC SRB121FU
Modul ini merupakan kompak smart relay yang dikeluarkan oleh perusahaan komponen listrik terkemuka yaitu Schneider Electric. Dasar pemilihan modul ini sebagai kontrol otomatisasi dikarenakan kemampuan menggunakan diskrete input dan suplai tegangan arus bolak balik dari 100 sampai dengan 240 volt. Sehingga tidak diperlukan power suplai dc seperti kebanyakan modul PLC lainya. Tentu saja ini memudahkan aplikasi dilapangan yang hanya tersedia sumber tanaga AC 220 volt.

Modul ini mempunyai dikrete input sebanyak delapan poin dengan output relay sebanyak 4 poin, dimana hal sudah sangat mencukupi untuk mengontrol otomatisasi interlock antara pompa air baku pretreatment dan pompa kimia. 


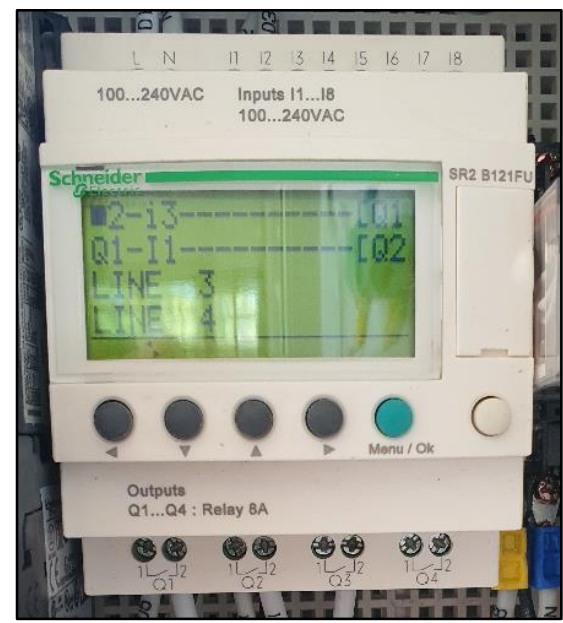

Gambar 4. Modul PLC SRB121FU

\subsection{Metodologi}

Metode yang digunakan pada aplikasi ini adalah kombinasi 1 buah pressure switch, 2 buah level kontrol pada tangki air baku dan tangki air bersih serta 1 buah modul plc smart relay SRB121FU untuk mengontrol pompa injeksi larutan oksidator bekerja bersamaan dengan pompa air baku ketika melakukan penyaringan, dengan kondisi sebagai berikut :

(1) Pompa pretreatment mengalirkan air baku dari tangki air baku air sumur ke tiga buah tabung filter filter, untuk dihilangkan polutan kasarnya.kemudian ditampung sebagai bahan baku air minum pada tangka air bersih.

(2) Pada saat yang bersamaan pressure switch yang terdapat pada pompa air baku yang sedang dalam kondisi Normally Closed akan memberikan input sinyal berupa arus listrik pada tegangan 220 volt ke input modul smart relay.

(3) Pada kondisi ini program didalam plc akan meneruskan output berupa arus listrik untuk menghidupkan pompa kimia larutan $\quad \mathrm{KMnO}_{4} \quad$ sebagai oksidator.

(4) Kondisi sebaliknya ketika pressure switch berhenti bekerja maka pompa air baku dan pompa kimia akan berhenti bekerja secara bersamaan. 


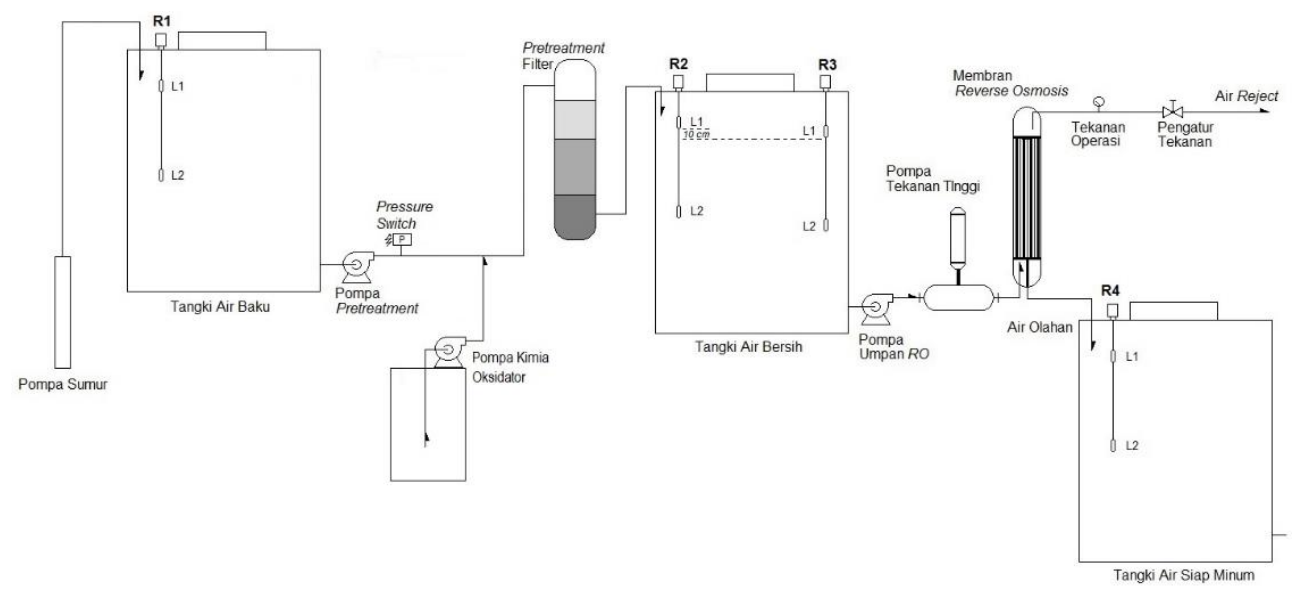

Gambar 5. Flow chart proses suplai air baku sebagai umpan air siap minum

\section{HASIL DAN PEMBAHASAN}

Dengan memperhatikan

Gambar 6. maka dapat dijelaskan secara rinci proses otomatisasi pompa injeksi larutan oksidator terhadap pompa air baku.

(1) Pompa pretreatment mengalirkan air baku menuju pretreatment filter melewati pressure switch dan injector kimia.

(2) Seting tekanan tinggi pada pressure switch diseting 4 $\mathrm{kgf} / \mathrm{cm} 2$, sedangkan untuk diffrencial pada tekanan rendah diseting pada angka 2,7 kgf/cm2.

(3) Pada saat tekanan air belum mencapai batasan seting tinggi, maka arus listrik pada pressure switch akan mengalir dari poin 1 ke 2. Ini juga akan memberi input arus listrik pada I1 pada smart relay SRB121FU dan menjalankan program yang menghasilkan output Q2 yang menjalankan pompa kimia oksidator.

(4) Selama tangki air bersih belum terisi penuh hingga menyentuh batas atas L1 level kontrol R2, maka pompa air baku akan terus hidup. Ini disebabkan level kontrol mensuplai arus input 12 pada smart relay SRB121FU dan menjalankan program yang menghasilkan output Q1 yang menjalankan pompa air baku.

(5) Jika air pada tangki air baku berada di bawah level L2 pada pelampunga radar $\mathrm{R} 1$ yang mana artinya tangki air baku dalam kedaan kosong ini akan memutus suplai arus input 12 yang terhubung seri dengan 13 keadaan ini memutus suplai arus ke output Q1 dan mematikan pompa air baku juga memutus arus output Q2 yang mematikan pompa oksidator.

(6) Apabila dalam keadaan tertentu dilakukan backwash pada pretreatment filter, maka stop 
valve ditutup secara manual sehingga mengakibatkan tekanan pressure switch mencapai seting batas atas yaitu $4 \mathrm{kgf} / \mathrm{cm}^{2}$, kondisi ini juga memutus suplai arus ke kumparan motor pompa air baku dan memutus aliran suplai arus input 11 dan mematikan pompa kimia oksidator .

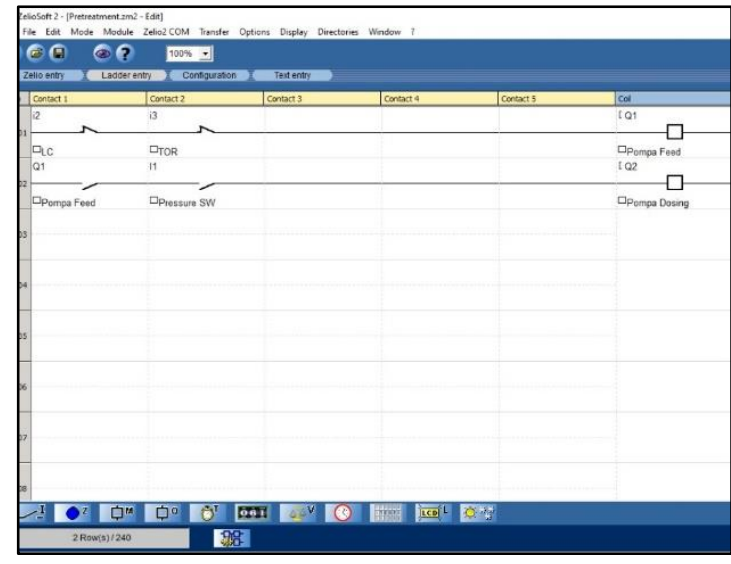

Gambar 6. Wiring diagram pada program Zelio Soft smart relay SRB121FU

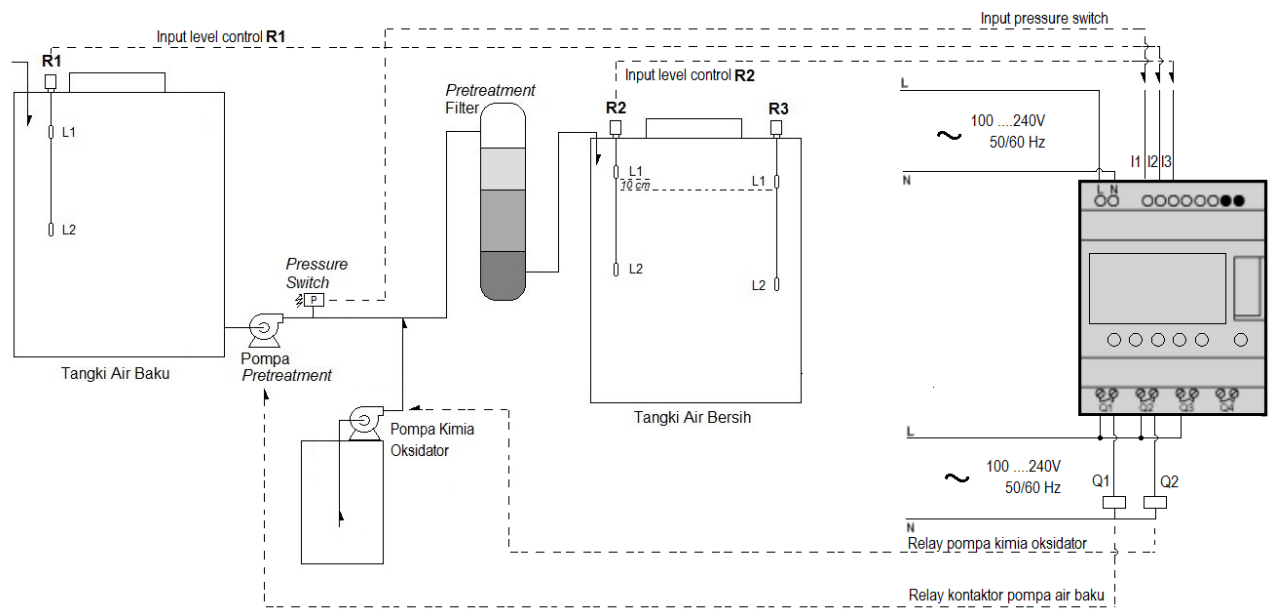

Gambar 7. Skema kontrol otomatisasi pompa dosing oksidator

\section{KESIMPULAN}

Unit Arsinum ini terdiri dari beberapa peralatan pompa yang digerakkan oleh tenaga listrik. Kunci dari sistim ini adalah kontrol yang baik untuk mengintegrasikan peralatan- peralatan tersebut sehingga peralatan tersebut tidak menyusahkan operator ketika dioperasikan. Ketersediaan suku cadang di sekitar lokasi menjadi unsur penting jika terjadi kerusakan, inilah yang menjadi pertimbangan 
pada saat pemilihan radar pelampung untuk mengontrol tangki-tangki pada unit ini, terutama tangki air baku dan tangka air bersih, tangki ini harus dipasang minimal radar untuk memberi sinyal ke panel pompa pretreatment dimana didalam nya terdapat modul PLC Smart Relay hingga dapat mengontrol mati hidup pompa sesuai level air dan juga berdasarkan tekanan. Diharapkan dengan aplikasi ini dapat terjadi efisiensi pemakaian bahan kimia oksidator pada penolahan air minum ini secara keseluruhan.

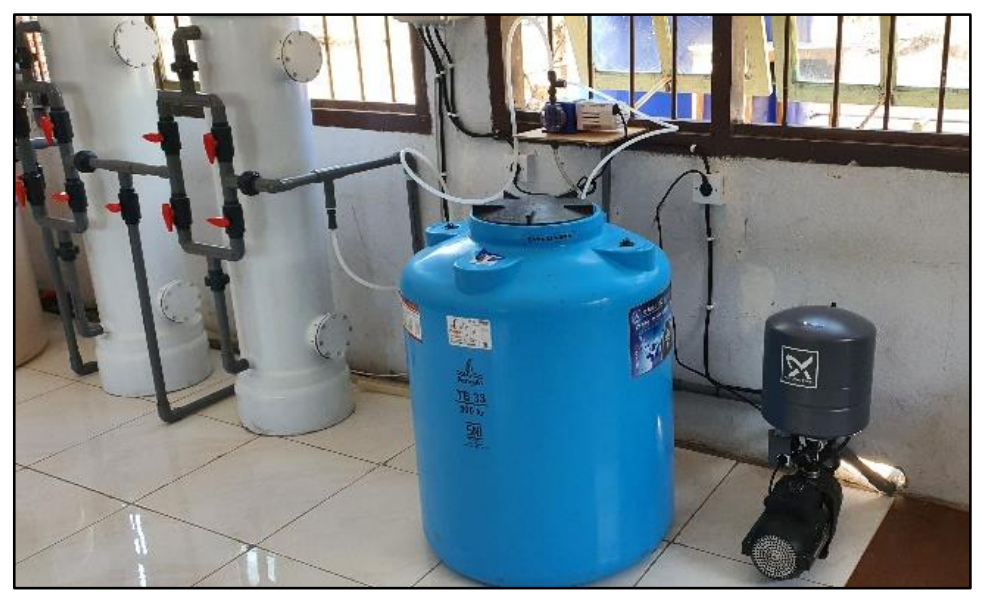

Gambar 8. Pressure switch,pada pompa air baku dan pompa kimia oksidator

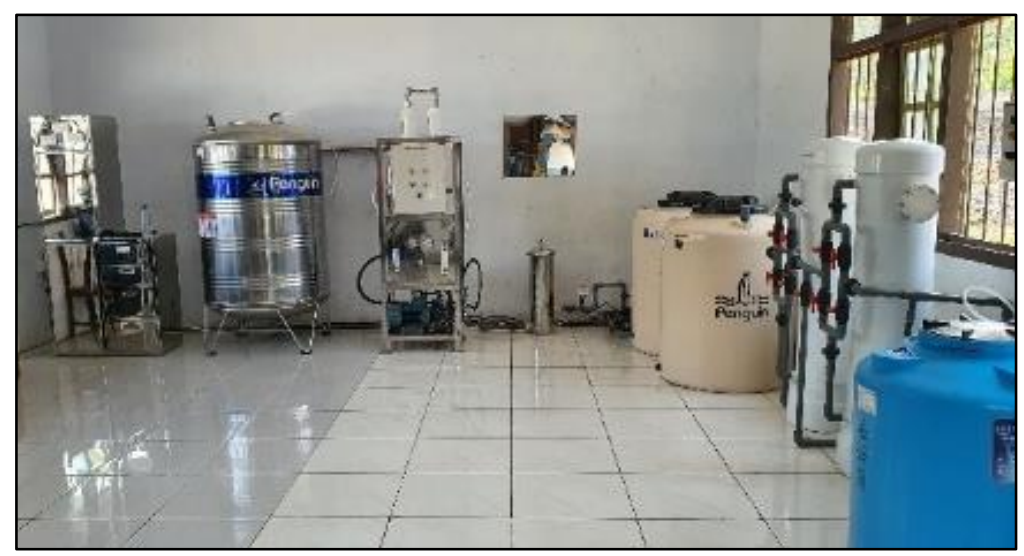

Gambar 9. Tangki air bersih, tangki kimia, dan pretreatment filter 


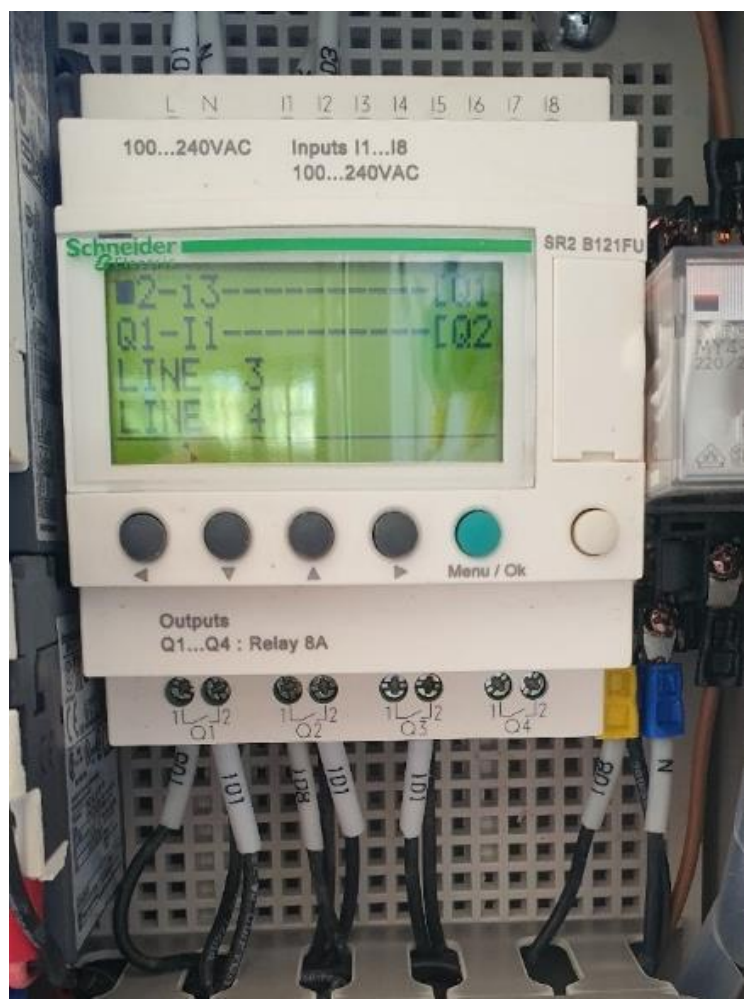

Gambar 9. Unit penyaringan membrane UF dan $R O$

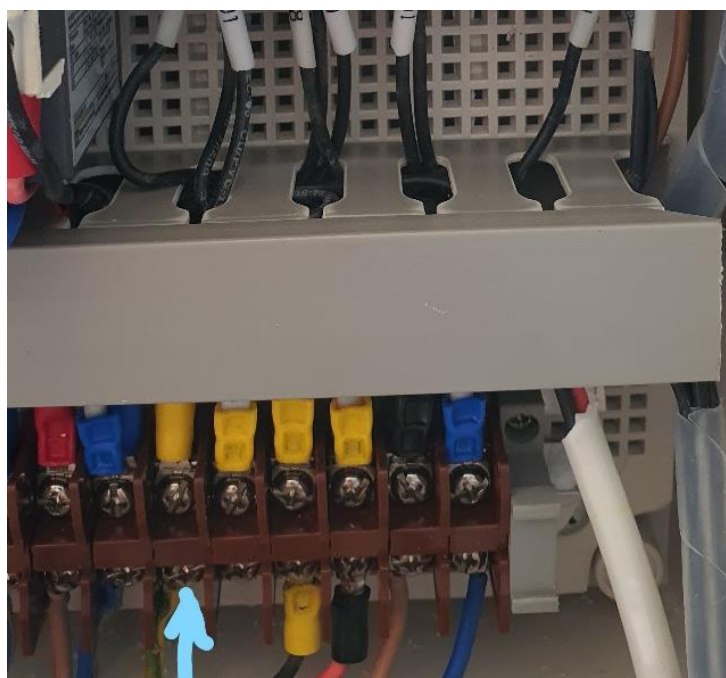

Gambar 10. Panel kontrol pretreatment filter, input dari pressure switch 


\section{DAFTAR PUSTAKA}

Sugeng, Yusril, SISTIM KENDALI POMPA AIR BERSIH PADA GEDUNG BERTINGKAT, JREC (Journal of Electrical and Electronics) Volume 2, Number 1, 2014

http://www.wikikomponen.com/prinsi p-dan-cara-kerja-mesin-pompaair/

http://jakartapiranti.com/blog/pengert ian-pompa-transfer/

Grundfos Basic Data Book

https://www.saginomiya.co.jp/en/aut o/syousai.php?File=./pdf/sys.pdf \&Mode $=5 \&$ NameType $=$ SINGLE \%20FUNCTION\%2OPRESSURE $\% 20$ CONTROLS\&Type2=sys

https://www.pulsafeeder.co.id/chemt ech/

https://www.se.com/ww/en/product/F YG22/pressure-switch-fyg-7-bar--adjustable-scale-2-thresholds--2ncl

https://download.schneiderelectric.com/files?p_enDocType= Catalog\&p_File_Name=Catalog+ Zelio+Logic+Smart+relays++English++September+2018.pdf\&p_Doc_R ef=DIA3ED2111202EN 